\title{
A National Survey of Self-Prescription of Beta-Blockers and Their Relation to Undiscovered Anxiety Among Medical and Pharmacological Students in Saudi Arabia
}

This article was published in the following Dove Press journal:

Neuropsychiatric Disease and Treatment

\begin{abstract}
Albaraa Alsini (iD)
Ishraq Alkhodaidi ${ }^{2}$

Yasir Alsini ${ }^{3}$

Sarh Alsseeni ${ }^{4}$

Shrooq Alkhodaidi ${ }^{5}$

Ehsan Alsini ${ }^{6}$

Asim Alsini ${ }^{7}$

Hamzah Sindi ${ }^{8}$

Khaled Alswat ${ }^{9}$

'Resident, Department of Otolaryngology Head \& Neck Surgery, Alhada Armed Forces Hospital, Taif, Saudi Arabia; ${ }^{2}$ Medical Student, Faculty of Medicine, Taif University, Taif, Saudi Arabia; ${ }^{3}$ PharmD, Alhada Armed Forces Hospital, Taif, Saudi Arabia; ${ }^{4}$ PharmD Student, Taif University, Taif, Saudi Arabia; ${ }^{5}$ Resident, Department of Dermatology, King Abdulaziz Hospital, Makkah, Saudi Arabia; ${ }^{6}$ PharmD, Medical Representative in Eli Lilly and Company, Taif, Saudi Arabia; ${ }^{7}$ Medical Intern, Faculty of Medicine, Taif University, Taif, Saudi Arabia; ${ }^{8}$ Medical Student, Faculty of Medicine, Umm AlQura University, Makkah, Saudi Arabia; ${ }^{9}$ Professor of Medicine, Department of Medicine, School of Medicine, Taif University, Taif, 21944, Saudi Arabia
\end{abstract}

Correspondence: Albaraa Alsini Department of Otolaryngology Head \& Neck Surgery, Alhada Armed Forces Hospital, Alhada District, Taif, Saudi Arabia

Tel +96653000620I

Email Dr.albaraa2015@gmail.com
Background: The development of beta-blocker (BB) medications is considered one of the most critical milestones of drug research. Several trials showed possible anti-anxiety effects of BBs. Our primary goal is to investigate the prevalence of anxiety disorder and the use of BBs as anxiolytic without medical prescription among medical and pharmacological students in Saudi Arabia.

Methods: A cross-sectional study was conducted at multiple universities in Saudi Arabia. Students were given a questionnaire containing 44 questions that included demographic data, school location, BB usage behavior, GPA status before and after using BBs, and a GAD-7 anxiety screening questionnaire.

Results: A total of 3326 mainly female senior students participated in the study with a mean age of $21.9 \pm 1.7$ years. According to the GAD-7 score, half of the sampled students did not meet criteria indicative of anxiety disorder, and one-third were considered to have mild anxiety with a significant positive correlation between the BB usage and the GAD-7 score. A total of $6.4 \%$ of the sample reported usage of BBs. Therapeutics and Internal Medicine were the most common subjects for which BBs were used. When compared to pharmacy students, medical students were more likely to be male, smokers, diagnosed with psychiatric illness, having a higher mean GAD-7 score, report BB usage, and correctly identified common and serious BB side effects.

Conclusion: The inappropriate use of BB drugs without medical advice might have shortand long-term effects, and those may be more vulnerable to have psychological issues in the future. Our findings shed light on the need to identify students who are taking BBs as being at high risk of underlying anxiety disorders.

Keywords: beta-blocker, anxiety, student anxiety, self-prescription, undiagnosed anxiety

\section{Introduction}

Beta-blocker (BB) drugs are considered one of the most critical milestones of drugs of all time. Not long after the time when BBs were discovered in the early 1960s, ${ }^{1}$ these medications became a focus of importance in psychiatry. Therefore, several trials for the possible anti-anxiety effects had followed this discovery. Several trials studied its effective role in the treatment of anxiety, addiction and withdrawal symptoms, schizophrenia, stage fright, and performance anxiety. ${ }^{2}$

BBs are also used to control cardiovascular disorders that involve angina, tremors, hypertension, and arrhythmias., ${ }^{3,4}$ They achieve slowing of the heart rate 
in both patients and healthy people through a combination of decreasing sympathetic outflow and blocking betaadrenergic receptors. ${ }^{5}$ Despite the medical indications, many recent studies illustrated the increasing use of BBs over time. ${ }^{6}$

Physicians showed great concerns about BB side effects especially non-selective BBs which are associated with more adverse effects, are more commonly used for anxiety (ie, propranolol). Such as BB-induced weight gain and adverse metabolic effects. Moreover, BBs are associated with a slightly increased risk of type II diabetes mellitus. Non-selective BBs may also exacerbate asthmatic attacks due to their blockage of the B2-adrenergic receptors and may need to be avoided in respiratory patients. ${ }^{7}$

Generalized anxiety disorder (GAD) is characterized by six persistent disabling anxiety symptoms for at least six months. Anxiety disorders are one of the common mental illnesses in the community. Their strong adverse effect on patients' life quality is a major reported concern. Despite the availability of their effective treatment, these disorders may still be underdiagnosed and undertreated. ${ }^{8}$

Test anxiety is unpleasant feeling of tension with autonomic system activation that occurs when being assessed for performance or clinical examination. ${ }^{9}$ Students are more prone to experiencing stress due to the nature of their daily work, which may adversely affect their mental health and academic performance. In particular, medical and pharmacological students are more likely to worry about many life and academic issues. Consequently, they are prone to practice different stress-relieving methods. The most common method is the use of medications, such as BBs, to overcome performance anxiety. ${ }^{10}$

Short-term memory-related tasks such as exam preparation and public speaking are more sensitive to the negative effects of stress; therefore, tension and stress can reduce performance quality. Propranolol indeed helps in reducing stress, which improves intellectual tasks and the overall exam performance. ${ }^{11-13}$

A national, non-random online poll for the nonmedical uses of prescription drugs by the journal Nature reported that $20 \%$ of participants used prescription drugs to improve their concentration for a particular task. Of those polled, $15 \%$ had taken BBs such as propranolol. ${ }^{14}$ Controlled double-blinded trials showed that propranolol has positive outcomes in treating anxiety. ${ }^{15,16}$

Self-medication involves using nonprescription medicines, often over-the-counter (OTC) drugs. These are typically used for minor self-diagnosed conditions without a physician's supervision. ${ }^{17}$

Self-medication includes purchasing drugs without a prescription, sharing medications with others, or taking drugs available at home for a prolonged period. This is due to the easy accessibility of drugs in Saudi Arabia, with no need for having medical prescriptions. People can acquire prescribed medicines, such as anti-acne treatments and antibiotics, over-the-counter. ${ }^{18}$

The self-prescription of BBs is increasing among the students due to easy availability in pharmacies and the students' specific medical knowledge. ${ }^{19,20}$ Due to its previously mentioned adverse effects, further analysis, and a better understanding of this matter are essential. Safety protocols and measures need to be applied to prevent students' self-prescription behavior.

To the best of our knowledge, this is the first large national study in Saudi Arabia to investigate the use of BBs among medical and pharmacy students as an over-the -counter (OTC) medication. Our primary goal is to investigate the prevalence of anxiety disorder and the use of BBs as an anxiolytic without medical prescription among medical and pharmacological students in Saudi Arabia. Furthermore, we will evaluate the effect of BBs on exam performance and the awareness of BB side effects.

\section{Methods}

A cross-sectional study was conducted among medical and pharmacological students in Saudi Arabia. We included all healthy medical and pharmacological students in Saudi Arabia regardless of age, gender, nationality and level. We excluded students with an active psychiatric or chronic illness such as hypertension who were diagnosed before and actively following with their physician. The questionnaire was developed after several reviews by the research team. The questionnaire was composed of 44 questions divided into five parts. The first part included demographic data, school location, educational level of participants, smoking and shisha status (Smoking pipe), and frequency of energy drink consumption. The second part of the questionnaire was applied to identify participants who have chronic diseases, known psychiatric illnesses, or hand tremors. The third part included tasks to identify participants who used BBs before exams and seminars, the reasons for using BBs, GPA status assessed before and after using BBs have been used, knowledge of the side effects of BBs, and real-life experiences of such effect were assessed as well. The fourth part assessed whether another person had recommended the BBs to students and self- 
prescription as well; the thought of harmfulness of misuse of BBs was evaluated; also, other self-prescribed medications were evaluated other than BBs. The fifth part was a GAD-7 questionnaire, which is an anxiety screening tool, containing seven items to evaluate the anxiety symptoms in the past two weeks. The GAD-7 score ranges from 0 to 21 . The anxiety severity was indicated by the measured score, which is gathered through the answered GAD-7 questionnaire. Those students who did not have anxiety scored less than five in GAD-7, while those scoring 5-9, 10-14, and $\geq 15$ were considered to have mild, moderate, and severe anxiety, respectively.

A student from different universities has been contacted and agreed to help in data collection. A group was created, and then the questionnaire was explained to each one of the data collectors. A hard-copy questionnaire was distributed among medical and pharmacological students from different universities in Saudi Arabia. All students agreed to participate before filling the questionnaire. One of the research teams who distributes the questionnaire was available for any inquiry. All data collectors from different regions in Saudi Arabia sent the data files to the main investigator.

The data extracted to excel sheet then export to the Statistical Package for Social Sciences (SPSS) for analysis. We defined statistical significance as $\mathrm{p}<0.05$. $t$-tests were used for continuous variables and chi-squared tests were performed for categorical variables, and unpaired.

\section{Result}

A total of 3326 students participated in the study with a mean age of $21.9 \pm 1.7$ years (Table 1). The sample consisted of mainly female medical students, senior students attending government universities in the western Saudi region. Approximately one-fifth of the sample reports smoking cigarettes, Shisha or Argela. Most of them reported no or rare consumption of energy drinks. Although approximately $16 \%$ of the samples reported chronic medical or existed psychiatric disorders, interestingly, $20.6 \%$ report hands tremor. Threefourths of the participants report being diagnosed with psychiatric disorders before college enrollment, with depression, social phobia, and anxiety being the most common disorders reported. According to the GAD-7 score, half of the sample was normal, and one-third was considered to have mild anxiety.

Of those sampled, $6.4 \%$ reported usage of $\mathrm{BBs}$, mostly before the clinical exams, seminar presentations, and the theory exam (Table 2). Internists and psychiatrists were the most common providers to prescribe $\mathrm{BBs}$, while students' course material and advice from college students of the same level were the most common source for the non-prescribed BBs usage. The most common reason for BBs usage was feeling anxious on the exam day and the subjective feeling that the student will do better with BBs usage. Therapeutics and Internal Medicine were the most common subjects for which BBs were used. A quarter of the BBs users experienced related side effects, with only a few of the participating students correctly identified the common or serious side effects of BBs. Most of the students report no change in their GPA with the usage of BBs. More than half of the students believe that nonprescribed BBs are harmful. Self-prescription was common among the BBs users, with analgesics and antibiotics being the most common self-prescribed medications.

When compared to pharmacy students, medical students were more likely to be male ( $\mathrm{P}<0.001)$, to be private university students $(\mathrm{P}<0.001)$, to be smokers $(0.078)$, to be diagnosed with psychiatric illness ( $P$ 0.012), to have depression (P 0.043), to have a higher mean GAD-7 score (P 0.266), to have reported BBs usage (P 0.285), as using BBs because of being anxious or not feeling well prepared for the exam ( $\mathrm{P}$ 0.034), as mostly avoiding self-prescribed medications ( $\mathrm{P}<0.001)$, and as correctly identifying common and serious side effects of BBs (P 0.297 and P 0.071, respectively) (Table 3 ).

Female respondents were more likely to use BBs when compared to males (Figure 1). Moreover, there was a significant positive relationship between the usage of BBs and the GAD-7 score (Figure 2). Partial correlation adjusting for school location, bachelor's degree specialty, age, gender, smoking, chronic illness, existed psychiatric illness, and tremor showed a non-significant negative correlation between BBs usage and GAD-7 score ( $\mathrm{r}$ - 0.181, P 0.193).

\section{Discussion}

Test anxiety is unpleasant feeling of tension with autonomic system activation that occurs when being assessed for performance or clinical examination. ${ }^{9}$ Medical education around the globe is considered one of the most demanding training programs; subsequently, much commitment, time, and emotion are necessary. ${ }^{21}$ Such pressure may have a negative impact on student psychology and can trigger anxiety and depression. ${ }^{22,23}$ Anxiety is common among the general population, but it is often undetected and untreated. ${ }^{24,25}$ Anxious people can experience various kinds of symptoms, including fear, palpitations, abdominal pain, shortness of breath, and urinary incontinence. ${ }^{26}$ The prevalence of a large range of 
Table I Baseline Characteristics for the Whole Cohort

\begin{tabular}{|c|c|}
\hline \multicolumn{2}{|l|}{ Baseline Characteristics $(N=3326)$} \\
\hline Mean age (years) & $21.9 \pm 1.7$ \\
\hline Male (\%) & 33.0 \\
\hline Medical students (\%) & 79.6 \\
\hline Pharmacy students (\%) & 20.4 \\
\hline Government university (\%) & 94.1 \\
\hline Junior student (\%) & 41.5 \\
\hline Senior student (\%) & 56.4 \\
\hline Intern (\%) & 1.1 \\
\hline Graduated (\%) & 1.0 \\
\hline \multicolumn{2}{|l|}{ Location of the college } \\
\hline Western region of Saudi (\%) & 25.8 \\
\hline Eastern region of Saudi (\%) & 16.4 \\
\hline Northern region of Saudi (\%) & 11.9 \\
\hline Southern region of Saudi (\%) & 23.6 \\
\hline Central region of Saudi (\%) & 22.4 \\
\hline \multicolumn{2}{|l|}{ Lifestyle habits } \\
\hline Cigarette smokers \% & 8.6 \\
\hline Shisha/Argela smokers \% & 9.9 \\
\hline No energy drinking consumption \% & 57.9 \\
\hline Daily energy drinking consumption \% & 4.6 \\
\hline Weekly energy drinking consumption \% & 9.7 \\
\hline Rarely energy drinking consumption \% & 27.8 \\
\hline \multicolumn{2}{|l|}{ Comorbid conditions } \\
\hline Chronic medical diseases (\%) & 8.8 \\
\hline Existed psychiatric disorders \% & 7.4 \\
\hline Hands tremor (\%) & 20.6 \\
\hline \multicolumn{2}{|l|}{ Chronic medical disease diagnosis } \\
\hline Asthma and allergy (\%) & 2.7 \\
\hline \multicolumn{2}{|l|}{ Existed Psychiatric diagnosis } \\
\hline Anxiety (\%) & 1.8 \\
\hline Schizophrenia (\%) & 0.3 \\
\hline Depression (\%) & 2.2 \\
\hline Obsessive compulsive disorders (\%) & 0.7 \\
\hline
\end{tabular}

(Continued)
Table I (Continued).

Baseline Characteristics $(\mathbf{N}=3326)$

Existed other psychiatric disorders

\begin{tabular}{|l|c|}
\hline Panic disorders (\%) & 1.5 \\
\hline Social phobia (\%) & 2.0 \\
\hline Post-traumatic stress disorder (\%) & 0.1 \\
\hline Diagnosis was made before college enrolment (\%) & 74.1 \\
\hline Screening with Generalized Anxiety Disorders 7-items (GAD-7) \\
\hline Mean GAD-7 score (SD) & $5.3 \pm 5.1$ \\
\hline Normal (\%) & 51.2 \\
\hline Mild anxiety (\%) & 29.8 \\
\hline Moderate anxiety (\%) & 12.2 \\
\hline Sever anxiety (\%) & 6.8 \\
\hline
\end{tabular}

anxieties among medical students outside North America had been reported in between $7.7 \%$ and $65.5 \%$ of individuals. ${ }^{27} \mathrm{We}$ reported $15 \%$ of $\mathrm{BB}$ users are self-prescribers, which is within the literature-reported range; the main reason was they were studied well, but $53 \%$ feel anxious in exams, and $31 \%$ of users were feeling more confident in exams. Anxiety among medical and pharmacological students warrants special attention as it can affect academic performance and dropout rates. ${ }^{28}$ Medical students are predisposed to different types of stress, such as studying overload, lack of sleep, financial burdens, student abuse, and exposure to deaths of patients; all these factors are possible causes for the high rate of anxiety. ${ }^{29-32}$ Our study demonstrated mild anxiety in 30\% of medical and pharmacological students which is consistent with the literature. BBs are used to control cardiovascular disorders that involve angina, tremors, hypertension, and arrhythmias. ${ }^{3,4}$ Exam- and stressrelated anxiety symptoms can also be relieved by BBs. ${ }^{33}$ Students gained a wide knowledge about drugs in medical school and self-prescribed as a common practice. ${ }^{34-36}$ The sources of information regarding the uses of BBs before exams in the present study were $37 \%$ and $32 \%$ from material studying and friends, respectively.

Propranolol is one of the common self-prescribed drugs among medical, pharmacological, and dental students. ${ }^{33,37-39}$ A single-institution national study among students in 2015 reported that exam performance was improved with users of BBs. ${ }^{37}$ In the present study, we found the majority of BB users 
Table 2 Prevalence and Characteristics of Beta-Blockers Usage

\begin{tabular}{|c|c|}
\hline \multicolumn{2}{|l|}{ Baseline Characteristics } \\
\hline Overall Beta blocker usage (\%) & 6.4 \\
\hline Beta blocker usage before all the exams (\%) & 1.0 \\
\hline Beta blocker usage before most of the exams (\%) & 1.4 \\
\hline Beta blocker usage before some of the exams (\%) & 4.0 \\
\hline Beta blocker usage before theory exam (\%) & 3.5 \\
\hline Beta blocker usage before clinical exam (\%) & 4.7 \\
\hline Beta blocker usage before seminar presentation (\%) & 4.3 \\
\hline Beta blockers prescribed by a health care providers (\%) & 29.9 \\
\hline Self-prescribed medications other than Beta blockers (\%) & 15.1 \\
\hline \multicolumn{2}{|l|}{ Reason of Beta blockers usage } \\
\hline I did not study well for the exam (\%) & 15.0 \\
\hline I studied well, but feels anxious on the exam day (\%) & 53.5 \\
\hline I feel more confident/will do better on the exam if I take it (\%) & 31.5 \\
\hline \multicolumn{2}{|l|}{ Exam fields where Beta blockers was used for } \\
\hline Internal medicine (\%) & 22.6 \\
\hline General surgery $(\%)$ & 12.3 \\
\hline Obstetrics/Gynecology (\%) & 14.2 \\
\hline Pediatrics (\%) & 0.1 \\
\hline Biology (\%) & 0.1 \\
\hline Biochemistry (\%) & 7.5 \\
\hline Pharmacology (\%) & 2.3 \\
\hline Therapeutic (\%) & 37.7 \\
\hline Others (\%) & 3.2 \\
\hline \multicolumn{2}{|l|}{ Final scores for the topics after Beta blockers usage } \\
\hline GPA improved after Beta-blockers use (\%) & 32.3 \\
\hline GPA unchanged after Beta-blockers use (\%) & 60.0 \\
\hline GPA worsen after Beta-blockers use (\%) & 7.0 \\
\hline$A+\operatorname{or} A(\%)$ & 18.1 \\
\hline $\mathrm{B}+$ or $\mathrm{B}(\%)$ & 51.6 \\
\hline $\mathrm{C}+$ or $\mathrm{C}(\%)$ & 22.6 \\
\hline$D+$ or $D(\%)$ & 7.7 \\
\hline Did you ever failed an exam after using beta-blocker pills? (\%) & 17.5 \\
\hline
\end{tabular}

(Continued)
Table 2 (Continued).

\begin{tabular}{|c|c|}
\hline \multicolumn{2}{|l|}{ Baseline Characteristics } \\
\hline Experienced side effects related to Beta blockers usage (\%) & 24.0 \\
\hline $\begin{array}{l}\text { Do you think non-prescribed Beta blockers usage is harmful? } \\
\text { (\%) }\end{array}$ & 63.9 \\
\hline $\begin{array}{l}\text { Study participants whom were able to identify correctly two } \\
\text { common side effects (\%) }\end{array}$ & 2.7 \\
\hline $\begin{array}{l}\text { Study participants whom were able to identify correctly two } \\
\text { serious side effects (\%) }\end{array}$ & 5.2 \\
\hline \multicolumn{2}{|l|}{$\begin{array}{l}\text { Specialty of the health care providers for those who prescribed Beta } \\
\text { blockers }\end{array}$} \\
\hline General practitioner (\%) & 23.3 \\
\hline Family physician (\%) & 23.3 \\
\hline Internal medicine doctor (\%) & 26.7 \\
\hline Psychiatric doctor (\%) & 25.6 \\
\hline \multicolumn{2}{|l|}{ Beta blockers users' source of advice/information } \\
\hline Study materials in college (\%) & 37.4 \\
\hline Same level college student (\%) & 32.5 \\
\hline Senior college colleagues (\%) & 25.2 \\
\hline Junior college colleagues (\%) & 4.9 \\
\hline $\begin{array}{l}\text { Did you review any evidence for Beta blockers usage before } \\
\text { the exam? }\end{array}$ & 23.9 \\
\hline \multicolumn{2}{|l|}{$\begin{array}{l}\text { Types of the medication that is self-prescribed other than Beta } \\
\text { blockers }\end{array}$} \\
\hline Antibiotic (\%) & 13.8 \\
\hline Antihistamine (\%) & 10.7 \\
\hline Analgesic (\%) & 29.8 \\
\hline Others (\%) & 26 \\
\hline
\end{tabular}

have the same GPA despite using BBs for exam performance, and approximately $32 \%$ had grade improvement. Abukhalaf et al conducted a survey among 885 students in a single institution and found $17 \%$ used BBs without medical prescription, and the usage was five times more among medical students than dental students. However, the side effects of using BBs, such as hypotension, shortness of breath, and fainting, were experienced by $1.7 \%$ of users. ${ }^{37}$ We found that $24 \%$ of participants had experienced BB side effects. However, only $2 \%$ and 5\% knew the common and serious side effects, respectively. Most participants in the present study (63\%) agreed with the harmfulness of non-prescribed BBs. 
Table 3 Group Characteristics Based on the College of the Participants

\begin{tabular}{|c|c|c|c|}
\hline Baseline Characteristics & Medicine & Pharmacy & $P$ value \\
\hline Number of participants (\%) & 79.6 & 20.4 & $\mathrm{n} / \mathrm{a}$ \\
\hline Mean age (years) & $21.8 \pm 1.7$ & $21.9 \pm 1.6$ & 0.172 \\
\hline Male (\%) & 34.8 & 25.1 & $<0.001$ \\
\hline Government university (\%) & 93.4 & 97.1 & $<0.001$ \\
\hline Junior student (\%) & 42.0 & 38.8 & \multirow[t]{4}{*}{$<0.001$} \\
\hline Senior student (\%) & 57.2 & 54.2 & \\
\hline Intern (\%) & 0.4 & 3.8 & \\
\hline Graduated (\%) & 0.4 & 3.2 & \\
\hline \multicolumn{4}{|l|}{ Lifestyle habits } \\
\hline Cigarette smokers \% & 9.0 & 6.9 & 0.078 \\
\hline Shisha/Argila smokers \% & 10.0 & 9.6 & 0.763 \\
\hline No energy drinking consumption \% & 58.9 & 54.5 & \multirow[t]{4}{*}{0.400} \\
\hline Daily energy drinking consumption \% & 4.4 & 5.2 & \\
\hline Weekly energy drinking consumption \% & 8.2 & 15.1 & \\
\hline Rarely energy drinking consumption \% & 28.5 & 25.2 & \\
\hline \multicolumn{4}{|l|}{ Comorbid conditions } \\
\hline Chronic medical diseases (\%) & 9.3 & 6.9 & 0.046 \\
\hline Existed psychiatric disorders \% & 7.9 & 5.1 & 0.012 \\
\hline Hands tremor (\%) & 20.4 & 21.6 & 0.484 \\
\hline \multicolumn{4}{|l|}{ Existed Psychiatric diagnosis } \\
\hline Anxiety (\%) & 2.0 & 1.2 & 0.184 \\
\hline Schizophrenia (\%) & 0.3 & 0.3 & 0.893 \\
\hline Depression (\%) & 2.5 & 1.2 & 0.043 \\
\hline Obsessive compulsive disorders (\%) & 0.8 & 0.5 & 0.379 \\
\hline \multicolumn{4}{|l|}{ Existed other psychiatric disorders } \\
\hline Panic disorders (\%) & 1.6 & 0.1 & 0.283 \\
\hline Social phobia (\%) & 2.1 & 1.5 & 0.283 \\
\hline Post-traumatic stress disorder (\%) & 0.1 & 0.1 & 0.737 \\
\hline \multicolumn{4}{|c|}{ Screening with Generalized Anxiety Disorders 7-items (GAD-7) } \\
\hline Mean GAD-7 score (SD) & $5.4 \pm 5.1$ & $5.1 \pm 5.4$ & 0.266 \\
\hline Normal (\%) & 50.9 & 53.3 & \multirow[t]{4}{*}{0.968} \\
\hline Mild anxiety (\%) & 30.2 & 28.2 & \\
\hline Moderate anxiety (\%) & 12.2 & 11.8 & \\
\hline Sever anxiety (\%) & 6.7 & 6.7 & \\
\hline
\end{tabular}


Table 3 (Continued).

\begin{tabular}{|c|c|c|c|}
\hline Baseline Characteristics & Medicine & Pharmacy & $P$ value \\
\hline Overall Beta blocker usage (\%) & 6.5 & 6.2 & 0.285 \\
\hline Beta blocker usage before all the exams (\%) & 0.1 & 1.6 & \multirow[t]{3}{*}{0.285} \\
\hline Beta blocker usage before most of the exams (\%) & 1.2 & 2.2 & \\
\hline Beta blocker usage before some of the exams (\%) & 4.4 & 2.4 & \\
\hline Beta blocker usage before theory exam (\%) & 3.2 & 4.7 & 0.061 \\
\hline Beta blocker usage before clinical exam (\%) & 5.2 & 2.7 & 0.007 \\
\hline Beta blocker usage before seminar presentation (\%) & 4.1 & 5.1 & 0.276 \\
\hline Beta blockers prescribed by health care providers (\%) & 29.7 & 30.6 & 0.262 \\
\hline Self-prescribed medications other than Beta blockers (\%) & 13.4 & 21.3 & $<0.001$ \\
\hline Feels better during the exam that students took Beta blockers for (\%) & 57.9 & 53.3 & 0.858 \\
\hline \multicolumn{4}{|l|}{ Reason of Beta blockers usage } \\
\hline I did not study well for the exam (\%) & 16.7 & 7.1 & \multirow[t]{3}{*}{0.034} \\
\hline I studied well, but feels anxious on the exam day (\%) & 56.5 & 42.9 & \\
\hline I feel more confident/will do better on the exam if I take it (\%) & 26.8 & 50.0 & \\
\hline \multicolumn{4}{|l|}{ Final scores for the topics after Beta blockers usage } \\
\hline GPA improved after Beta-blockers use (\%) & 30.2 & 40.5 & \multirow[t]{2}{*}{0.625} \\
\hline GPA worsen after Beta-blockers use (\%) & 6.9 & 7.1 & \\
\hline $\mathrm{A}+$ or $\mathrm{A}(\%)$ & 14.8 & 28.6 & \multirow[t]{4}{*}{0.268} \\
\hline $\mathrm{B}+$ or $\mathrm{B}(\%)$ & 53.4 & 45.2 & \\
\hline$C+$ or $C(\%)$ & 24.4 & 16.7 & \\
\hline $\mathrm{D}+$ or $\mathrm{D}(\%)$ & 7.4 & 9.5 & \\
\hline Did you ever failed an exam after using beta-blocker pills? (\%) & 16.7 & 21.7 & 0.724 \\
\hline \multicolumn{4}{|l|}{ Beta blockers harms } \\
\hline Experienced side effects related to Beta blockers usage (\%) & 24.6 & 21.7 & 0.915 \\
\hline Do you think non-prescribed Beta blockers usage is harmful? (\%) & 63.6 & 65.0 & 0.040 \\
\hline Study participants whom were able to identify correctly two common side effects (\%) & 2.9 & 2.4 & 0.297 \\
\hline Study participants whom were able to identify correctly two serious side effects (\%) & 5.5 & 4.0 & 0.071 \\
\hline \multicolumn{4}{|l|}{ Beta blockers users' source of advice/information } \\
\hline Study materials in college (\%) & 34.2 & 48.6 & \multirow[t]{4}{*}{0.233} \\
\hline Same level college student (\%) & 34.7 & 23.1 & \\
\hline Senior college colleagues $(\%)$ & 25.0 & 28.3 & \\
\hline Junior college colleagues (\%) & 6.1 & 0.0 & \\
\hline Did you review any evidence for Beta blockers usage before the exam? & 20.2 & 38.0 & $<0.001$ \\
\hline
\end{tabular}


Table 3 (Continued).

\begin{tabular}{|c|c|c|c|}
\hline Baseline Characteristics & Medicine & Pharmacy & $P$ value \\
\hline Antibiotic (\%) & 12.6 & 16.2 & \multirow[t]{4}{*}{0.062} \\
\hline Antihistamine (\%) & 12.6 & 7.1 & \\
\hline Analgesic (\%) & 27.9 & 33.3 & \\
\hline Others (\%) & 24.2 & 29.3 & \\
\hline
\end{tabular}

Interestingly, Butt et al published a study in 2016 where they found that students who take BBs before exams are at significantly more risk of taking an antidepressant in the future and have a higher rate of suicide attempts than nonBB users. ${ }^{35}$ Therefore, wide awareness is needed of the fact that $\mathrm{BB}$ users before exams might be more vulnerable to psychological issues and need special attention.

Present study has several strengths including large sample size and been the first onsite study done at multiple universities in different regions of Saudi Arabia.

Despite these strengths, this study has several limitations. Present study is a questionnaire-based study, a student who has chronic illnesses or psychiatric disorder was self-reported and not from a national database or contacting treating physician.
Although the GAD-7 is a validated screening questionnaire, the healthy student who has high score was not evaluated by psychiatric physician.

\section{Conclusion}

The inappropriate use of $\mathrm{BB}$ drugs without medical advice might have short- and long-term effects, and those users may be more vulnerable to having psychological issues in the future. Our findings shed light on the need to take measures to identify students who are taking $\mathrm{BB}$ drugs as being at a high risk of underlying anxiety disorders. We suggest implementing a national student support program to help the students with stress and anxiety in different ways rather than using BBs unless indicated.

\section{BETA BLOCKERS USEAGE}

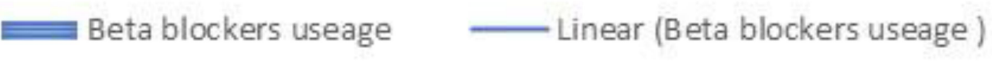

8

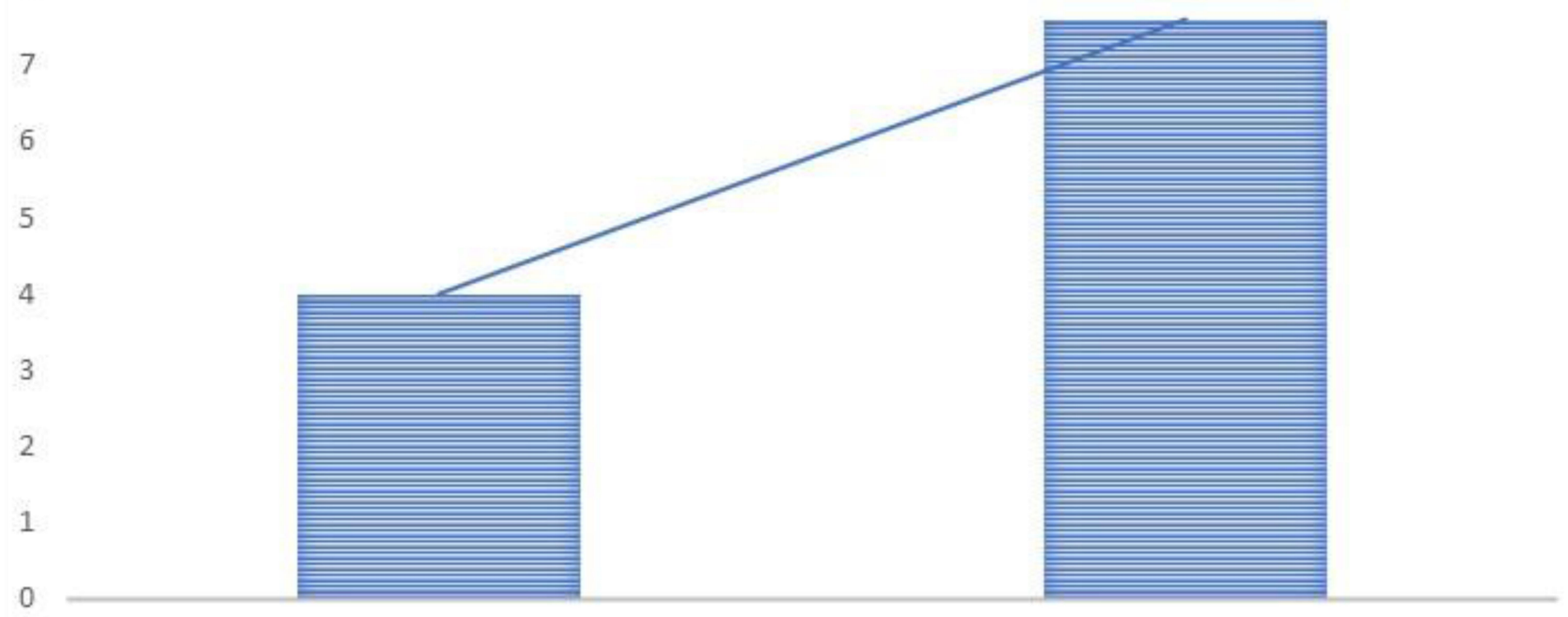

Male

Female

Figure I Beta blockers usage based on gender (\%). $P$ value $<0.00$ I. 


\section{BETA BLOCKERS USAGE}

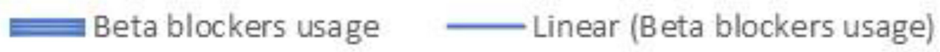

14
12
10
8
6
4
2
0

GAD-7 score $<5$

\section{4}

2

10

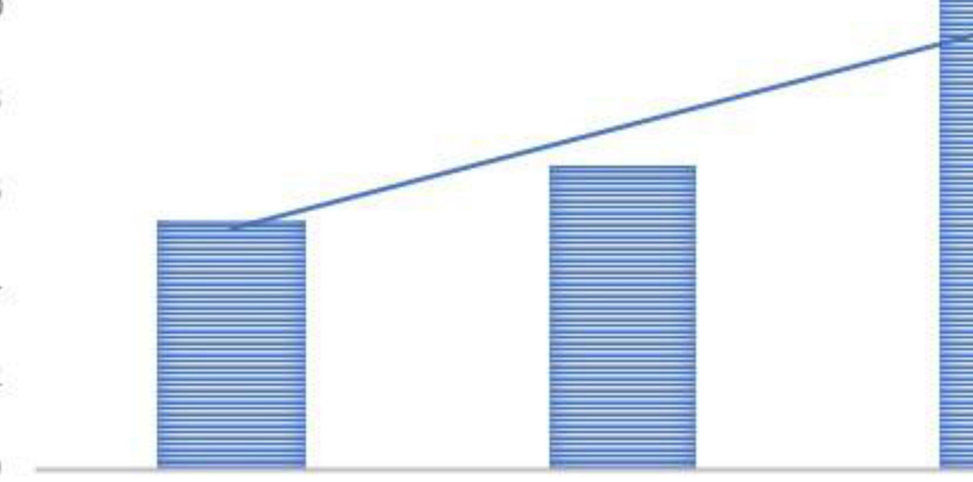

GAD-7 score 5-9

Figure 2 Beta blockers usage based on GAD-7 screening. $P$ value 0.009 .

\section{Ethical Approval and Consent}

The study was conducted in accordance with the Declaration of Helsinki. All students agreed to participate before filling the questionnaire. The research project was approved by the research ethical committee at Taif university (Approval number 42-0047).

\section{Acknowledgment}

We would like to acknowledge the Taif University Research Support Project Number (TURSP-2020/37), Taif University, P.O.Box 11099, Taif 21944, Saudi Arabia for supporting this project.

We also would like to acknowledge all data collectors from different universities, we could not conduct the study without their tremendous effort. Eman Ali Albrahim $^{1}$, Fatimah Abdullatif Alabbad ${ }^{1}$, Nosibah Khaled Telmesani ${ }^{1}$, Maram Mubarak Alqahtani ${ }^{1}$, Fozia Khalaf Alsugair ${ }^{1}$, Lateefah Talal Alshammari ${ }^{1}$, Basim Faiqe Khan ${ }^{1}$, Zahra Abdulwahed Alsaeed ${ }^{1}$, Renad momammed Almohammedi ${ }^{2}$, Othman Mohammed Alobaid $^{2}$, Shooq Fahad Alfadel ${ }^{2}$, Tahani Nasser Alrashidi $^{3}$, Ahad Massad Almohammadi ${ }^{3}$, Haifa Mohammad Alshammary ${ }^{4}$, Hajar Ghassab Alruwaili ${ }^{4}$, Meshari Hamed Altowairqi ${ }^{5}$, Yousef Zaben Alotibi $^{5}$, Mashael Mohammed Alharthi $^{5}$, Asmaa Turki
Altowairqi ${ }^{5}$, Reem Mohammed noor Kalakattawi ${ }^{5}$, Amal Turki Altowairqi ${ }^{5}$, Abdullah Ammah Alharbi ${ }^{5}$, Turki Dubayan Altowairqi ${ }^{5}$, Afnan Mohammed Kalakattawi $^{5}$, Safiyh Ahmad Alasiri ${ }^{6}$, Reem Awad Alqhatani $^{6}$, Mariam Ali Suhluli ${ }^{6}$, Ahmed Ibrahim Asiri ${ }^{6}$, Amani Mohammed Alwadei ${ }^{7}$, Norah Saad Aljohani ${ }^{7}$, Alanood Mohammed Alwadei ${ }^{7}$, Rahaf Suhail Alotaibi ${ }^{8}$, Wa'ad Abdullah Alzaher ${ }^{8}$, Altaf Mohammed Almoallem $^{8}$, Rawan Zienelabdein Mahgoub ${ }^{9}$, Ebtehag Faham Alsulami ${ }^{10}$, Mohammed Ahmed Safhi ${ }^{10}$, Ahmed Muhdar Omar ${ }^{10}$, Faisal Salem Alqhtani ${ }^{10}$, Maram Jawad Alshammary $^{11}$, Ahoud Faisal Altamimi ${ }^{11}$, Nouf Abdulrahman Alromaih ${ }^{11}$, Wejdan Saad Alrawaili ${ }^{12}$, Amal Abdullah Albuqaisi ${ }^{12}$, Mashael Eissa Alfaifi ${ }^{13}$, Mohannad Faisal Tobaigy ${ }^{13}$, Rehab Mohammed Alhamoud $^{13}$, Nuha Abker Areeshi ${ }^{13}$, Nouf Mousa Moqri $^{13}$, Sara Ali Halawi ${ }^{13}$, Rahmah Naif Alzaid ${ }^{14}$, Abdulmajeed Oqla Alnosair ${ }^{14}$, Muath Ali Alshehri ${ }^{15}$, Mohammed Ali Alshehri ${ }^{16}$.

${ }^{1}$ Imam Abdulrahman Bin Faisal university in Dammam

${ }^{2}$ King Saud bin Abdulaziz University for Health Sciences

${ }^{3}$ Tabuk university

${ }^{4}$ Northern Border university

${ }^{5}$ Taif university 
${ }^{6}$ King Khalid university

${ }^{7}$ Najran university

${ }^{8}$ Princess Nora Bint Abdulrahman university

${ }^{9}$ Dar Aluloom university

${ }^{10}$ King Abdulaziz university

${ }^{11}$ Qassim university

${ }^{12}$ Hail university

${ }^{13}$ Jazan university

${ }^{14}$ Aljouf university

${ }^{15}$ Almaarefa university

${ }^{16}$ Imam Mohammed Bin Saud Islamic University.

\section{Funding}

This project was supported by the Taif University Research Support Project Number (TURSP-2020/37), Taif University, Taif, Saudi Arabia.

\section{Disclosure}

Authors have no conflicts of interest to report in this work.

\section{References}

1. Quirke V. Putting theory into practice: james Black, receptor theory and the development of the beta-blockers at ICI, 1958-1978. Med Hist. 2006;50(1):69-92. doi:10.1017/S0025727300009455

2. Steenen SA et al. Propranolol for the treatment of anxiety disorders: systematic review and meta-analysis. $J$ Psychopharmacol. 2016;30 (2):128-139. doi:10.1177/0269881115612236

3. Chen S, Wang -J-J, Wang -Q-Q, et al. The effect of carvedilol and propranolol on portal hypertension in patients with cirrhosis: a meta-analysis. Patient Prefer Adherence. 2015;9:961-970. doi:10.2147/PPA.S84762

4. Lampropoulos KM, Sokolis DP, Dimitriou CA, et al. The effect of propranolol on aortic structure and function in normotensive rats. Hellenic J Cardiol. 2012;53(2):101-107.

5. Bollinger A, Gander M, Forster G. [Pulse rate and functional capacity before and after beta-receptor blockade with propranolol]. Schweiz Med Wochenschr. 1965;95(32):1075-1079.

6. Argulian E, Bangalore S, Messerli FH. Misconceptions and Facts About Beta-Blockers. Am J Med. 2019;132(7):816-819. doi:10.1016/ j.amjmed.2019.01.039

7. Egan BM. Cardioprotection: the role of beta-blocker therapy. J Clin Hypertens. 2005;7(7):409-416. doi:10.1111/j.1524-6175.2005.04486.x

8. Costa e Silva JA. The public health impact of anxiety disorders: a WHO perspective. Acta Psychiatr Scand Suppl. 1998;393(p):2-5. doi:10.1111/j.1600-0447.1998.tb05959.x

9. Martin RD, Naziruddin Z. Systematic Review of Student Anxiety and Performance During Objective Structured Clinical Examinations. Currents in Pharmacy Teaching and Learning; 2020.

10. Kadison R. Getting an edge-use of stimulants and antidepressants in college. $N$ Engl J Med. 2005;353(11):1089-1091. doi:10.1056/ NEJMp058047

11. Brewer C. Beneficial effect of beta-adrenergic blockade on "exam. nerves". Lancet. 1972;2(7774):435. doi:10.1016/S0140-6736(72) 91840-5

12. Alexander JK, Hillier A, Smith RM, et al. Beta-adrenergic modulation of cognitive flexibility during stress. J Cogn Neurosci. 2007;19 (3):468-478. doi:10.1162/jocn.2007.19.3.468
13. Faigel HC. The effect of beta blockade on stress-induced cognitive dysfunction in adolescents. Clin Pediatr (Phila). 1991;30 (7):441-445. doi:10.1177/000992289103000706

14. Maher B. Poll results: look who's doping. Nature. 2008;452 (7188):674-675. doi:10.1038/452674a

15. Granville-Grossman KL, Turner P. The effect of propranolol on anxiety. Lancet. 1966;1(7441):788-790. doi:10.1016/S0140-6736(66)91863-0

16. Wheatley D. Comparative effects of propranolol and chlordiazepoxide in anxiety states. Br J Psychiatry. 1969;115(529):1411-1412. doi:10.1192/bjp.115.529.1411

17. Du Y, Knopf H. Self-medication among children and adolescents in Germany: results of the National Health Survey for Children and Adolescents (KiGGS). Br J Clin Pharmacol. 2009;68(4):599-608. doi:10.1111/j.1365-2125.2009.03477.x

18. Albatti TH, Alawwad S, Aldueb R, et al. The self medication use among adolescents aged between 13-18 years old; Prevalence and behavior, riyadh -kingdom of Saudi Arabia, from 2014-2015. Int $J$ Pediatr Adolesc Med. 2017;4(1):19-25. doi:10.1016/j. ijpam.2016.05.001

19. Bruce TJ, Saeed SA. Social anxiety disorder: a common, underrecognized mental disorder. Am Fam Physician. 1999;60 (8):2311-2320.

20. Blanco C, Bragdon LB, Schneier FR, et al. The evidence-based pharmacotherapy of social anxiety disorder. Int $J$ Neuropsychopharmacol. 2013;16(1):235-249. doi:10.1017/ S1461145712000119

21. Wolf TM. Stress, coping and health: enhancing well-being during medical school. Med Edu. 1994;28(1):8-17. doi:10.1111/j.13652923.1994.tb02679.x

22. Mosley TH. Stress, Coping, and Well-Being Among Third-Year Medical Students. Academic Medicine; 1994.

23. Aktekin M, Karaman T, Senol YY, et al. Anxiety, depression and stressful life events among medical students: a prospective study in Antalya, Turkey. Med Edu. 2001;35(1):12-17. doi:10.1046/j.13652923.2001.00726.x

24. Weiller E, Bisserbe J-C, Maier W, et al. Prevalence and recognition of anxiety syndromes in five European primary care settings: a report from the WHO study on psychological problems in general health care. $B r \quad J$ Psychiatry. 1998;173(S34):18-23. doi:10.1192/ S0007125000293471

25. Kroenke K, Spitzer RL, Williams JBW, et al. Anxiety disorders in primary care: prevalence, impairment, comorbidity, and detection. Ann Intern Med. 2007;146(5):317-325. doi:10.7326/0003-4819-1465-200703060-00004

26. Testa A, Giannuzzi R, Sollazzo F, et al. Psychiatric emergencies (part I): psychiatric disorders causing organic symptoms. Eur Rev Med Pharmacol Sci. 2013;17(1 Suppl):55-64.

27. Hope V, Henderson M. Medical student depression, anxiety and distress outside North America: a systematic review. Med Edu. 2014;48(10):963-979. doi:10.1111/medu.12512

28. Dyrbye LN, Thomas MR, Shanafelt TD. Systematic review of depression, anxiety, and other indicators of psychological distress among US and Canadian medical students. Acad Med. 2006;81 (4):354-373. doi:10.1097/00001888-200604000-00009

29. Guthrie E, Black D, Shaw CM, et al. Embarking upon a medical career: psychological morbidity in first year medical students. Med Edu. 1995;29(5):337-341. doi:10.1111/j.1365-2923.1995.tb00022.x

30. Wolf TM. Graduating Medical Students' Ratings of Stresses, Pleasures, and Coping Strategies. Journal of Medical Education; 1988.

31. Williams CM, Wilson CC, Olsen CH. Dying, death, and medical education: student voices. J Palliat Med. 2005;8(2):372-381. doi:10.1089/jpm.2005.8.372

32. Richman JA, Flaherty JA, Rospenda KM, Christensen ML. Mental health consequences and correlates of reported medical student abuse. JAMA. 1992;267(5):692-694. doi:10.1001/jama.1992. 03480050096032 
33. Butt JH, Dalsgaard S, Torp-Pedersen C, Køber L, et al. Beta-blockers for exams identify students at high risk of psychiatric morbidity. J Child Adolesc Psychopharmacol. 2017;27(3):266-273. doi:10.10 89/cap.2016.0079

34. Tesfamariam S, Anand IS, Kaleab G, et al. Self-medication with over the counter drugs, prevalence of risky practice and its associated factors in pharmacy outlets of Asmara, Eritrea. BMC Public Health. 2019;19(1):159. doi:10.1186/s12889-019-6470-5

35. Tuyishimire J, Okoya F, Adebayo AY, et al. Assessment of self-medication practices with antibiotics among undergraduate university students in Rwanda. Pan Afr Med J. 2019;33:33. doi:10.11604/pamj.2019.33.307.18139

36. Jember E, Feleke A, Debie A, Asrade G. Self-medication practices and associated factors among households at Gondar town, Northwest Ethiopia: a cross-sectional study. BMC Res Notes. 2019;12(1):1-7. doi:10.1186/s13104-019-4195-2
37. Abukhalaf AA, Alomar A, Alsalame N, et al. Inappropriate use of beta-blockers among medical and dental students at King Saud University, Riyadh. J Family Med Primary Care. 2020;9(8):4391. doi:10.4103/jfmpc.jfmpc_696_20

38. Drew P, Barnes J, Evans S. The effect of acute beta-adrenoceptor blockade on examination performance. Br J Clin Pharmacol. 1985;19 (6):783-786. doi:10.1111/j.1365-2125.1985.tb02714.x

39. Al-Mohrej OA, Al-Bani WM, AlShaalan NS, et al. Prevalence of self-prescribing propranolol among medical and dental students in Riyadh, Saudi Arabia: a cross-sectional study. Health Professions Educ. 2018;4(1):16-26. doi:10.1016/j.hpe.2016.10.001

\section{Publish your work in this journal}

Neuropsychiatric Disease and Treatment is an international, peerreviewed journal of clinical therapeutics and pharmacology focusing on concise rapid reporting of clinical or pre-clinical studies on a range of neuropsychiatric and neurological disorders. This journal is indexed on PubMed Central, the 'PsycINFO' database and CAS, and is the official journal of The International Neuropsychiatric Association (INA). The manuscript management system is completely online and includes a very quick and fair peer-review system, which is all easy to use. Visit http://www.dovepress.com/testimonials.php to read real quotes from published authors. 